\title{
Influência das eleições e dos políticos na composição da despesa pública dos municípios de Santa Catarina
}

Jonatan Lautenschlage*

\begin{abstract}
Resumo
Este trabalho examina a influência das eleições e dos traços dos municípios e dos prefeitos nas despesas dos municípios do Estado brasileiro de Santa Catarina. Foram realizadas estimações econométricas com base em dados anuais de 292 municípios catarinenses, observados entre 2003 e 2014. Os resultados sugerem que os prefeitos elevam as despesas com habitação e equipamentos coletivos em períodos eleitorais. Evidenciou-se, também, que o gênero, a formação superior e o alinhamento político ao governador de estado, têm influência na condução da política fiscal ao nível dos municípios catarinenses, assim como o nível do produto, a sua variação e as características demográficas.
\end{abstract}

Palavras-Chave: oportunismo; eleições; governos locais

\section{Influence of elections and politicians on the composition of public expenditures of Santa Catarina's municipalities}

\begin{abstract}
This work examines the influence of elections, as well, demographic and incumbents characteristics on the composition of municipal public expenditures of the Brazilian state of Santa Catarina. We used several econometrical estimations using annual data for 292 municipalities of Santa Catarina between 2003 and 2014. We found evidence of changes in housing and community amenities in election periods. The results suggest the personal characteristics of the mayor (gender, superior education, and the alignment with the governor), and the characteristics of municipalities influence the fiscal policy in the municipalities of Santa Catarina.
\end{abstract}

Keywords: opportunism; elections; local governments

JEL Classification: H7, K19, E62

\section{Introdução}

A hipótese de que os formuladores de políticas públicas são ditadores benevolentes, que somente buscam maximizar o bem-estar da sociedade, já foi há muito abandonada pela Economia Política. Com foco nos partidos e nas instituições, vários estudos demostraram que as políticas são condicionadas pelos objetivos dos governantes eleitos, que almejam manter-se no poder. Assim, os incentivos eleitorais podem influenciar as políticas, fazendo-as desviar do ótimo do ponto de vista do bem-estar social. Vários estudos evidenciaram que os incumbentes adotam medidas oportunistas para serem reeleitos (NORDHAUS, 1975; ROGOFF; SIBERT,

\footnotetext{
* Programa doutoral em Economia da Universidade do Minho - NIPE. Departamento de Economia e Relações Internacionais da Universidade Federal de Santa Catarina. E-mail: jlauten@eeg.uminho.pt
} 
1988; ROGOFF, 1990; VEIGA; VEIGA, 2007, DRAZEN; ESLAVA, 2010; SAKURAI; MENEZES-FILHO, 2011) e implementam políticas que favorecem os apoiantes e simpatizantes do seu partido (HIBBS, 1977; COX; MCCUBBINS, 1986; ALESINA, 1987; PETTERSON-LIDBOM, 2008; ALBOUY, 2013) ou os eleitores indecisos (LINDBECK; WEIBULL, 1987, 1993).

A competição eleitoral (FREY; SCHNEIDER 1978a,b; BESLEY et al., 2011; AIDT et al., 2011), a rotatividade no poder de partidos de ideologias diferentes (ALESINA; TABELLINI, 1990) e o alinhamento político entre diferentes níveis de governo, especialmente no que toca ao favorecimentos na distribuição das transferências intergovernamentais (VEIGA; PINHO, 2007; BROLLO; NANNICINI, 2012), também foram identificados como condicionantes das políticas econômicas. Há ainda estudos que enfatizam a influência de grupos de pressão (OLSON, 1965; BECKER, 1985; GROSSMAN; HELPMAN, 1996) e das instituições (como regras eleitorais e formas de governo - PERSSON; TABELINI, 2003 - e a existência de limitações ao número de mandatos no poder - BESLEY; CASE, 1995; ALT et al., 2011; KLEIN; SAKURAI, 2015; VEIGA; VEIGA, 2016) na definição das políticas públicas.

Mais recentemente, tem havido um incremento no interesse dos efeitos das características pessoais dos incumbentes na condução da política econômica. Entre os atributos analisados, o gênero (CHATTOPADHAY; DUFLO, 2004; SVALERYD, 2009; FERREIRA; GYOURKO, 2014; BHALOTRA; CLOTS-FIGUERAS, 2014), a idade (ALESINA et al, 2015), a classe social (CARNES; LUPU, 2015), a etnia (PANDE, 2003) e a educação (BESLEY et al, 2011; MARTÍNEZ-BRAVO, 2017) são os que têm recebido mais atenção.

Este artigo pretende contribuir para esta literatura, analisando se as eleições e as características dos prefeitos influenciam as decisões de política fiscal no estado de Santa Catarina. Foi construída uma extensa base de dados com informação ao nível dos municípios, de 2003 a 2014. Esta inclui informação sobre as componentes das despesas, assim como variáveis que captam o nível de desenvolvimento demográfico, educacional e econômico dos municípios, o nível de educação dos prefeitos, o gênero, a ideologia, a limitação de mandatos e o alinhamento político com níveis superiores de governo. São analisadas as despesas segundo a classificação funcional, de forma a fornecer uma visão mais detalhada das preferências dos incumbentes.

Estudos anteriores já confirmaram a existência de relações causais entre algumas características dos incumbentes e a condução da política fiscal nos municípios brasileiros (SAKURAI; MENEZES-FILHO, 2011; SAKURAI, 2009; e NAKAGUMA; BENDER, 2006). No entanto, eles somente levaram em consideração a ideologia e o alinhamento político. Já 
Lautenschlage (2017) e Lautenschlage (aceito para publicação) analisaram mais variáveis; contudo, utilizaram as despesas e receitas segundo a classificação econômica, e este trabalho pretende analisar como as eleições e os traços pessoais dos prefeitos catarinenses influenciam na condução da política fiscal, mas com foco na classificação funcional das despesas, o que ainda não foi realizado nem para o caso catarinense, nem para o caso brasileiro.

Os resultados sugerem que as eleições e as características dos incumbentes, nomeadamente, a ideologia, o gênero, a impossibilidade de buscar a reeleição e o alinhamento político entre o prefeito e o governador do estado, influenciam a política fiscal, alterando os níveis da despesa pública e a sua composição. Há indicativos de que os prefeitos catarinenses escolhem elevar as despesas com habitação e equipamentos coletivos nos anos com eleições, sugerindo um comportamento similar ao proposto por Rogoff (1990), no qual os incumbentes direcionam recursos às despesas com maior visibilidade ao eleitorado.

$\mathrm{O}$ resto do trabalho prossegue da seguinte maneira. Na próxima seção efetua-se a revisão da literatura que embasa o trabalho, assente na discussão sobre a relação entre as eleições e as características dos políticos e a política fiscal. A seção 3 descreve o federalismo fiscal brasileiro, a base de dados e a estratégia empírica. Os resultados empíricos são apresentados e discutidos na seção 4, e a seção final apresenta as conclusões do estudo.

\section{Revisão da literatura}

Ao analisar o estado de arte da literatura sobre as escolhas públicas, percebe-se que a investigação tem vindo a atribuir maior atenção à possibilidade de determinados traços pessoais dos governantes eleitos ${ }^{1}$ influenciarem a condução da política fiscal. $\mathrm{O}$ argumento base é de que estas caraterísticas podem influenciar as preferências dos governantes e, por conseguinte, condicionar as suas decisões. Entre as características analisadas destacam-se a ideologia, o gênero e o nível educacional dos governantes, assim como a semelhança partidária entre estes e os níveis superiores de governo. Como este trabalho investiga somente os governos locais catarinenses, e no Brasil, tal como na maioria das nações, as políticas monetária e cambial são de exclusiva competência do governo central, a análise vai incidir apenas sobre a política fiscal. Ao utilizar dados municipais, consegue-se controlar para o arcabouço institucional, dado que todas as localidades são regidas pelas mesmas normas legais.

\footnotetext{
${ }^{1}$ Moessinger (2014) expandiu a investigação para as características do ministro das finanças na condução das políticas macroeconômicas.
} 
Revista Catarinense de Economia - RCE

APEC - Associação dos Pesquisadores em Economia Catarinense

$2^{\circ}$ Semestre de 2017 - www.apec.pro.br/rce

\subsection{Eleições e política fiscal}

A influência das eleições sobre as políticas macroeconômicas tem sido amplamente estudadas pela escola das escolhas públicas (public choice). Nordhaus (1977), em seu trabalho seminal, argumenta que os políticos são oportunistas e farão uso dos mecanismos de política econômica para que haja uma queda no desemprego e a manutenção do nível de preços, antes das eleições, com o intuito de serem recompensados nas urnas. Entretanto, após as votações, serão adotadas medidas contracionistas para que a economia volte ao seu nível inicial, com queda no emprego e elevação na taxa de inflação. Esse crescimento seguido por uma queda da economia, recebeu a denominação de ciclos político-econômicos, pois é gerado um ciclo econômico, baseado na política.

Rogoff e Sibert (1988) inovaram e deixaram de considerar as políticas macroeconômicas, passando a focar em manipulações nas contas públicas. Para Rogoff e Sibert (1988), os políticos também são oportunistas, mas, ao invés de reduzirem o desemprego, eles aumentam as despesas públicas antes das eleições, sinalizando competência aos seus eleitores. Entretanto, essa prática gera desequilíbrios orçamentários que deverão ser corrigidos no pós-eleição. Esse comportamento das despesas recebeu a denominação de ciclos político-orçamentários, dado que a manipulação ocorre na política fiscal. Ainda para Rogoff e Sibert (1988), essa prática logra melhores resultados eleitorais pela existência de uma assimetria de informação entre o político e os cidadãos.

Rogoff (1990) foi além de Rogoff e Sibert (1988) e introduziu a noção de que os políticos podem não alterar o nível da despesa total, entretanto, podem manipular a composição das despesas. Para Rogoff (1990), os políticos oportunistas elevam as despesas que melhor são recebidas pelo eleitorado e, assim, sinalizam maior competência. No caso analisado por Rogoff (1990), o autor evidenciou elevações nas despesas correntes antes das eleições, e o mesmo foi observado para o Brasil por Sakurai e Menezes-Filho (2011). Veiga e Veiga (2007) e Drazen e Eslava (2010) estudaram os governos locais de Portugal e Colômbia, respectivamente, e Nakaguma e Bender (2006) e Lautenschlage (2017) estudaram os estados brasileiros; Lautenschlage (aceito para publicação) fez o mesmo para os municípios de Santa Catarina.

\subsection{Ideologia e política fiscal}

Vários autores (HIBBS, 1977; ALESINA,1987; ALESINA; ROSENTHAL, 1995) argumentam que a ideologia dos políticos condiciona a condução da política macroeconômica, tanto no lado monetário, como no fiscal e o cambial. Os modelos teóricos de Hibbs (1977), Alesina (1987) e Alesina e Rosenthal (1995), diferem dos modelos oportunistas (NORDHAUS, 
1975; ROGOFF; SIBERT, 1988; ROGOFF, 1990), pois assumem que os governantes almejam a reeleição, mas possuem comportamentos diferentes consoante a sua ideologia, e procuram beneficiar, durante seus mandatos, os eleitores que os elegeram.

Para Hibbs (1977), os incumbentes de partidos de esquerda toleram maiores níveis de inflação, desde que, em contrapartida, haja menos desemprego. Os governantes de direita, por sua vez, não estão dispostos a abrir mão da estabilidade dos preços, mesmo que isso signifique menores níveis de emprego. Na parte fiscal, assume-se que os incumbentes de esquerda apresentam maiores níveis de despesa e, por conseguinte, de receitas tributárias. Os de direita preferem reduzir os gastos e assim, necessitam de menos recursos, o que se traduz em menor cobrança de impostos. Alesina (1987) argumenta que os políticos buscam maximizar as suas funções objetivo, que estão relacionadas com sua ideologia e são do conhecimento da população (eleitores racionais). Os eleitores escolhem seus governantes (ideologia) com base nas suas preferências (expectativas) relacionadas com os níveis de inflação, desemprego e crescimento. Entretanto, como os resultados das eleições são incertos e os contratos firmados são rígidos, surgem pequenas flutuações cíclicas na economia. ${ }^{2}$ Da mesma forma que Hibbs (1977), Alesina (1987) indica que os partidos de direita apresentarão menores níveis de inflação e crescimento e maiores de desemprego, enquanto os de esquerda apresentarão o oposto. No entanto, no modelo de Alesina (1987) as flutuações são pequenas e confinadas ao período em que ocorrem as eleições.

O impacto da ideologia também tem sido evidenciado na composição da despesa, indicando que as escolhas entre os diferentes dispêndios públicos podem estar relacionadas com a ideologia do incumbente. Kalseth e Rattso (1998) constataram que os governos locais noruegueses administrados pelo Partido Socialista (esquerda) apresentam maiores níveis de despesa com a administração pública, e Guillamón et al. (2013) evidenciaram que os municípios administrados por partidos conservadores (direita) apresentam maiores níveis de despesas com a polícia. Potrafke (2010) evidenciou que a ideologia do partido no poder na Alemanha tem impacto nos montantes despendidos com educação e cultura, enquanto Potrafke (2011) constatou, ao analisar as nações da OCDE, que os governos de esquerda tendiam a apresentar maiores níveis de gastos com serviços públicos, entre 1970 e 1997, e com educação, entre 1990 e 2006. Herwartz e Theilen (2014) constataram uma redução da influência da ideologia do político na condução das despesas em áreas sociais. Chortareas et al. (2016), por

\footnotetext{
${ }^{2}$ Alesina e Sachs (1988) constataram empiricamente, para o Governo Federal dos Estados Unidos, o fenômeno descrito por Alesina (1987).
} 
sua vez, não encontraram alterações na composição das despesas públicas locais na Grécia, relacionadas à ideologia.

No Brasil, a questão da ideologia é muito frouxa, como sustenta Mainwaring (1999). No entanto, em um estudo posterior para o Brasil, Sakurai (2009) concluiu que a ideologia dos prefeitos brasileiros tem impacto sobre os montantes despendidos com saúde e saneamento, habitação e urbanismo, comunicações, legislativo e educação e cultura. Sakurai e MenezesFilho (2011) constataram que os municípios liderados por governantes de esquerda e de direita apresentam menores níveis de despesas totais, quando comparados aos prefeitos de partidos de centro. ${ }^{3}$ Klein e Sakurai (2015), por sua vez, evidenciaram que prefeitos de esquerda apresentam maiores níveis de despesas correntes, quando comparados aos de partidos de centro e direita. Esses resultados indicam que, apesar dos prefeitos mudarem frequentemente de partido, existe evidência de que a ideologia influencia as suas decisões de política fiscal. ${ }^{4}$

\subsection{Alinhamento político e política fiscal}

Num Estado federado, as competências sobre a oferta de bens e serviços públicos são compartilhadas pelas diferentes esferas de governo. Essa divisão entre os níveis da administração pública varia de nação para nação. No Brasil, as responsabilidades no fornecimento de bens e serviços à população de cada uma das três esferas (União, estados e municípios) é determinada pela Constituição Federal. Cada uma das esferas elabora e aprova orçamentos próprios, indicando assim uma descentralização fiscal. As receitas, por sua vez, estão concentradas nas mãos da União, que transfere parte desses recursos aos níveis subnacionais. Os estados também enviam parte da sua arrecadação aos municípios que o compõem. Essa especificidade levanta uma questão relacionada com a possível relação entre os governantes dos diferentes níveis de governo. Ferreira e Bugarin (2007), Sakurai e MenezesFilho (2011) e Brollo e Nannicini (2012) constataram uma relação causal entre o alinhamento político envolvendo os níveis de governo e os níveis de transferências recebidas pelos municípios, que, dada a elevada concentração de recursos públicos no governo central, apresentam um impacto importante nos montantes despendidos pelas prefeituras brasileiras.

\footnotetext{
${ }^{3}$ Kneebone e Mckenzie (2001) ao analisarem os governos provinciais canadianos constataram que os governantes de diferentes partidos, agem de maneira diferente no que concerne à composição das despesas (classificação funcional) e receitas públicas. Veiga e Veiga (2007), também evidenciaram uma relação entre a ideologia e a composição da despesa pública (classificação econômica) dos governos locais portugueses.

${ }^{4}$ Nakaguma e Bender (2006) investigaram o impacto da ideologia na composição das despesas nos estados brasileiros e constataram que os governadores de esquerda despendem mais com educação e há indícios de que os mesmos, gastam mais com transporte.
} 
Posto isso, outro fator que pode influenciar nos níveis de despesa é o alinhamento político entre os diversos níveis de governo. Sakurai (2009) evidenciou que os prefeitos brasileiros aliados ao Presidente da República despedem menos com agricultura e legislativo, e os do mesmo partido do governador de estado gastam mais com saúde e saneamento, habitação e urbanismo e legislativo, e menos com agricultura, assistência e previdência e educação e cultura. Chortareas et al. (2016), por outro lado, não evidenciaram uma relação causal entre o alinhamento do governante local com o governo central grego, e a magnitude do oportunismo. ${ }^{5}$

\subsection{Nível educacional e política fiscal}

O Brasil já teve presidentes da República,${ }^{6}$ democraticamente eleitos, com doutorado (Fernando Henrique Cardoso e Michel Temer), com formação superior completa (Fernando Collor de Melo, Itamar Franco e Dilma Rousseff ${ }^{7}$ ) e também com somente educação básica (Luís Inácio Lula da Silva). Esses chefes do poder executivo brasileiro implementaram políticas fiscais com diferentes objetivos. Alguns desses chefes de governo despenderam mais com a administração pública e com a infraestrutura do País, enquanto outros focaram nas áreas de educação, saúde e habitação.

A relação entre o nível de estudo do governante e a economia tem sido, nos últimos anos, objeto de estudo das ciências econômicas, ${ }^{8}$ nomeadamente nas questões de crescimento econômico. Entretanto, a investigação tem migrado para a política fiscal, permitindo assim que se trace uma relação causal entre o grau de instrução do incumbente e decisões de política fiscal. Corneo e Grüner (2002) e Alesina e La Ferrara (2005) evidenciaram uma relação causal negativa entre o nível de estudo e rendimento e a preferência por medidas de redistribuição de rendimento. Já Alesina e Giuliano (2009), Hayo e Neumeier (2012) e Hayo e Neumeier (2014), argumentam que o fator mais importante é o nível de estudo e de rendimento dos pais do governante.

Ao analisar a composição da despesa, Jacobsen (2006) evidenciou que os governantes locais noruegueses com formação superior apresentam menores níveis gerais de despesa e

\footnotetext{
${ }^{5}$ Sakurai e Menezes-Filho (2011) concluíram que os prefeitos brasileiros alinhados ao presidente da república apresentam menores níveis de despesas com investimento e os alinhados ao governador de estado, além de despenderem menos despesas totais e arrecadarem mais tributos durante o mandato, manipulam mais as despesas totais e correntes em anos eleitorais.

6 Fonte: Presidência da República do Brasil. Disponível em: http://www.biblioteca.presidencia.gov.br/presidencia/ex-presidentes

${ }^{7}$ Frequentou a parte curricular do mestrado e doutorado, mas não obteve os graus de Mestre e Doutor, por não ter defendido a dissertação e tese, respectivamente.

${ }^{8}$ Para a relação causal entre líderes e crescimento econômico há os trabalhos de Jones e Olken (2005) e Besley et al. (2011). Dreher et al. (2009) investigou a relação entre a profissão e o grau de estudo dos governantes e a introdução de reformas econômicas.
} 
despendem menos com saúde, gastos sociais, desenvolvimento empresarial e serviços técnicos. Martínez-Bravo (2017) constatou que, nos distritos indonésios, os incumbentes com maior grau de estudo apresentam níveis mais elevados de provisão de bens e serviços públicos, nomeadamente centros de saúde, médicos e acesso à água potável.

\subsection{Gênero e política fiscal}

Ao redor do mundo, as mulheres têm sido relacionadas às despesas sociais. No Brasil há um programa social denominado Bolsa Família no qual os recursos são distribuídos, preferencialmente, às mães, sendo elas chefes de família ou não. Faz-se isso pois se considera que elas são mais responsáveis na alocação desse subsídio, ou seja, utilizam os recursos em alimentos e em itens que melhorem o bem-estar geral da família. Essa percepção pode ser extrapolada para a administração pública: Chattopadhyay e Duflo (2004) evidenciaram que quando os municípios das duas regiões indianas analisadas eram governados por mulheres, havia um aumento nas despesas com a provisão de água potável e estradas, enquanto que, quando um homem encabeçava o governo, as despesas com educação aumentavam.

Jacobsen (2006) concluiu que os prefeitos noruegueses do sexo masculino apresentam menores níveis de gastos com saúde, problemas sociais, educação infantil, cultura e desportos. Já Svaleryd (2009) constatou que, quando os municípios noruegueses são dirigidos por mulheres, se verifica um aumento das despesas com cuidados com as crianças e educação, em detrimento das despesas com os idosos. Esses resultados para os governos locais noruegueses são convergentes com outros. Os resultados obtidos por Park (2014) sugerem que os condados californianos governados por mulheres apresentam maiores níveis de gastos com bem-estar social, quando comparados aos seus congêneres do sexo masculino. ${ }^{9}$ No Brasil, a relação entre gênero e política físcal foi investigada por Lautenschlage (2017), para os estados, e Lautenschlage (aceito para publicação), para os municípios do estado de Santa Catarina. Em média, as governadoras dos estados brasileiros e as prefeitas catarinenses, quando comparadas aos seus congêneres do gênero masculino, apresentavam maiores níveis de despesas totais ao longo do mandato. No que concerne à composição da despesa, as governadores despendem mais com despesas correntes e as prefeitas de Santa Catarina, com pessoal. ${ }^{10}$

\footnotetext{
${ }^{9}$ Ferreira e Gyourko (2014) não evidenciaram relação causal entre o gênero e a composição da despesa

${ }^{10}$ Rehavi (2007) evidenciou que as legisladoras nos parlamentos estaduais norte-americanos votam mais favoravelmente, quando comparadas aos seus colegas de partido do sexo masculino, em matérias sobre despesas com saúde pública.
} 


\section{Estratégia empírica}

O Brasil é um país federativo com três níveis de governo: o governo federal, 27 estados e 5.570 municípios. As funções atuais de cada nível de governo foram definidas em 1988, após a aprovação da nova Constituição. Os municípios intervêm em diversas áreas, nomeadamente em água e saneamento, segurança social, educação, atividades recreativas, polícia, saúde, proteção contra incêndios, estradas. Algumas competências são compartilhadas com os governos estaduais e a União.

Nos municípios, o poder executivo recai sobre o prefeito, o vice-prefeito e os secretários. O prefeito e o vice-prefeito são eleitos por sufrágio universal direto, enquanto os secretários municipais são escolhidos pelo primeiro. Os governos locais podem permanecer no cargo por um período máximo de dois mandatos consecutivos de quatro anos. A legislatura é formada por vereadores, eleitos por representação proporcional. Eles aprovam as leis e supervisionam o poder executivo. Os poderes executivo e legislativo são independentes. As eleições locais para prefeitos e vereadores acontecem simultaneamente, sempre no primeiro domingo de outubro. Os prefeitos são eleitos de acordo com a regra da pluralidade. Em cidades com mais de 200 mil eleitores, no caso de nenhum dos candidatos obter mais de $50 \%$ dos votos, uma segunda rodada de eleições ocorre entre os dois principais contendores, após um mínimo de dez dias, também em um domingo de outubro.

Além da Constituição, a Lei de Responsabilidade Fiscal ${ }^{11}$ (LRF) também condiciona as decisões de política fiscal, definindo regras para a gestão das despesas, receitas e da dívida pública $^{12}$ para os três níveis de governo. De acordo com o LRF, todas as despesas públicas devem ter definida a sua fonte de financiamento, e existem limites para a dívida pública e para as despesas com pessoal. ${ }^{13}$ Os governos devem, também, definir e realizar metas fiscais trimestrais. Em caso de descumprimento, os prefeitos estão sujeitos a sanções penais e os municípios por eles governados estão impedidos de receber transferências do Governo Federal.

\subsection{Modelo econométrico}

Para que se possa atingir os objetivos traçados na introdução, far-se-á uso de estimações econométricas. A especificação básica do modelo utilizada na análise empírica é a que se segue:

$$
y_{j i t}=\text { Munic }_{i, t}^{\prime} \beta_{1}+\operatorname{Pref}_{i, t}^{\prime} \beta_{2}+\text { Eleição }_{i t} \beta_{3}+\mu_{i}+\varepsilon_{i t}
$$

\footnotetext{
${ }^{11}$ Lei Complementar $n^{\circ} 101$ de 04 de maio de 2000.

${ }^{12}$ Os limites de endividamento existem somente para os governos estaduais e municipais.

${ }^{13} 60 \%$ da receita corrente líquida, 54\% para o Poder Executivo e 6\% para o Legislativo
} 
onde, $y_{j i t}$ representa cada uma das componentes fiscais analisadas, uma para cada função da despesa $(j), i$ indica o município $(\mathrm{i}=1, \ldots 292)$ e $t$ indica o ano $(\mathrm{t}=2003, \ldots, 2014)$. Munic $_{i, t}^{\prime} \mathrm{e}$ $\operatorname{Pre} f_{i, t}^{\prime}$ são vetores compostos por variáveis que expressam as características dos municípios e dos prefeitos, respectivamente. A variável $E l e i c ̧ a ̃ o_{i t}$ assume o valor um, nos anos com eleições locais e zero caso contrário ${ }^{14} . \mu_{i}$ representa efeitos fixos e $\varepsilon_{i t}$ o termo de erro. Finalmente, $\beta_{1}$ a $\beta_{3}$ são coeficientes ou vetores de coeficientes a serem estimados.

\subsection{Variáveis e fontes de dados}

Inicia-se a descrição das variáveis pelas componentes da despesa, que no modelo 1 são representadas por $\mathrm{y}_{j i t}$. Para facilitar comparações internacionais e evitar um número excessivo de zeros em algumas séries, as categorias originais foram agregadas de acordo com a classificação do FMI, ${ }^{15}$ dado que a classificação funcional das despesas públicas brasileira compreende 28 categorias. ${ }^{16}$ Desta forma serão utilizadas as seguintes variáveis: ${ }^{17}$ DespTot $_{\text {it }}$ (Despesa total); ServGerAP ${ }_{i t}$ (Legislativa, Administração e Especiais); SegOrdPub $b_{i t}$ (Judiciária, Essencial e Segurança); ProtAmb Saneamento); Saúde (Saúde); DesRecCulRelit (Cultura e Desporto); Educaçãoit (Educação); ProtSocial $_{i t}$ (Assistência, Previdência e Cidadania) e AssunEcon ${ }_{i t}$ (Trabalho, Ciência, Agricultura, Indústria, Comércio, Energia e Transporte).

Os dados sobre os gastos municipais foram extraídos do banco de dados Finanças do Brasil - Dados Contábeis sobre os Municípios da Secretaria Nacional do Tesouro. A amostra abrange 292 municípios catarinenses de 2003 a 2014. Todos os dados estão expressos em termos de centenas de reais per capita e a preços constantes de 2016. O índice de preços utilizado para deflacionar os dados foi obtido da Fundação Getúlio Vargas (IGP-DI). A Tabela 1 apresenta as estatísticas descritivas das variáveis utilizadas no trabalho empírico.

14 Durante o período analisado neste estudo, ocorreram eleições locais em 2004, 2008 e 2012.

15 Serviços gerais da administração pública (ServGerAP); Segurança e ordem pública (SegOrdPub); Assuntos econômicos (AssunEcon); Proteção social (ProtAmb); Habitação e equipamentos coletivos (HabEqCol); Saúde (Saúde); Desportos, recreação, cultura e religião (DesRecCulRel); Educação (Educação); e Proteção social (ProtSoc).

${ }^{16}$ Legislativo, judiciária, essencial, administração, segurança, assistência, previdência, saúde, trabalho, educação, cultura, cidadania, urbanismo, habitação, saneamento, ambiental, ciência, agricultura, agrária, indústria, comércio, comunicações, energia, transporte, desporto e especiais.

${ }^{17}$ Entre parênteses estão expostas as funções segundo a classificação funcional em utilização no Brasil. 
Tabela 1 - Estatísticas descritivas

\begin{tabular}{|c|c|c|c|c|c|c|}
\hline & & (1) & (2) & (3) & (4) & (5) \\
\hline & Variáveis & $\mathrm{N}$ & Média & Desvio Padrão & Mínimo & Máximo \\
\hline & Ano & 2,794 & 2,008 & 3.342 & 2,003 & 2,014 \\
\hline Variável do Oportunismo & Eleição & 2,794 & 0.271 & 0.445 & 0 & 1 \\
\hline \multirow{6}{*}{ Características dos prefeitos } & Esquerda & 2,794 & 0.112 & 0.315 & 0 & 1 \\
\hline & Feminino & 2,794 & 0.0426 & 0.202 & 0 & 1 \\
\hline & Superior & 2,794 & 0.393 & 0.489 & 0 & 1 \\
\hline & Reeleito & 2,794 & 0.200 & 0.400 & 0 & 1 \\
\hline & Gov & 2,794 & 0.313 & 0.464 & 0 & 1 \\
\hline & Pres & 2,794 & 0.0941 & 0.292 & 0 & 1 \\
\hline \multirow{5}{*}{ Características dos municípios } & 1PIB & 2,784 & 25,104 & 11,970 & 7,268 & 179,428 \\
\hline & Crescimento & 2,784 & 955.6 & 5,245 & $-81,642$ & 99,513 \\
\hline & PES65 & 2,794 & 0.0670 & 0.0178 & 0.0317 & 0.136 \\
\hline & Urbano & 2,794 & 0.538 & 0.251 & 0.0980 & 1 \\
\hline & Analfabetos & 2,794 & 0.0843 & 0.0378 & 0.00910 & 0.229 \\
\hline \multirow{10}{*}{$\begin{array}{c}\text { Componentes da despesa } \\
\text { pública (classificação } \\
\text { funcional) }\end{array}$} & ServGerAp & 2,786 & 5.763 & 6.797 & 0 & 326.8 \\
\hline & SegOrdPub & 2,723 & 0.152 & 0.615 & 0 & 27.82 \\
\hline & AssunEcon & 2,786 & 5.668 & 5.003 & 0 & 56.61 \\
\hline & ProtAmb & 2,599 & 0.0881 & 0.277 & 0 & 4.014 \\
\hline & HabEqCol & 2,783 & 2.706 & 2.919 & 0 & 98.29 \\
\hline & Saúde & 2,771 & 5.932 & 3.780 & 0.000236 & 136.2 \\
\hline & DesRecCulRel & 2,786 & 0.601 & 0.660 & 0 & 9.759 \\
\hline & Educação & 2,778 & 6.925 & 5.404 & 1.624 & 247.2 \\
\hline & ProtSocial & 2,786 & 1.169 & 0.993 & 0 & 29.41 \\
\hline & DespTot & 2,794 & 29.06 & 21.05 & 7.896 & 884.9 \\
\hline
\end{tabular}

Nota: Todas as variáveis fiscais estão expressas em termos per capita (a preços constantes de 31 de dezembro de 2016)

No gráfico da Figura 1, está expressa a distribuição das despesas pelas três esferas de governo no Brasil. Nota-se, por exemplo, que os municípios são responsáveis por $81 \%$ da função $\mathrm{HabEqCol}$ (habitação e equipamentos coletivos), enquanto a participação da despesa com os segurança e ordem pública (SegOrdPub) pelos governos locais é de $4 \%$. Por fim, os municípios brasileiros são responsáveis por $12 \%$ das despesas públicas totais.

Dado que este trabalho pretende inovar ao avaliar como determinados traços dos políticos influenciam na condução da política fiscal, o vetor Pref, que inclui seis variáveis binárias, apresenta papel primordial, dado que o mesmo engloba as características pessoais dos prefeitos catarinenses. Feminino Fit $_{\text {e Superior }}$, identificam, respectivamente, prefeitas e prefeitos com grau universitário. Esquerda $a_{\mathrm{it}}$ assume o valor de 1 quando o chefe do poder local pertence a um partido de esquerda. ${ }^{18}$ Por fim, Pres $_{\text {it }}$ e $G_{o v}$ it são iguais a um quando o prefeito é do mesmo partido que o presidente da República ou o governador do estado, respectivamente.

\footnotetext{
${ }^{18}$ A classificação proposta pode Zucco (2011) foi utilizada para identificar os partidos de acordo com sua ideologia.
} 
Figura 1 - Brasil: distribuição das despesas entre as três esferas de governo, segundo a classificação funcional - 2016.

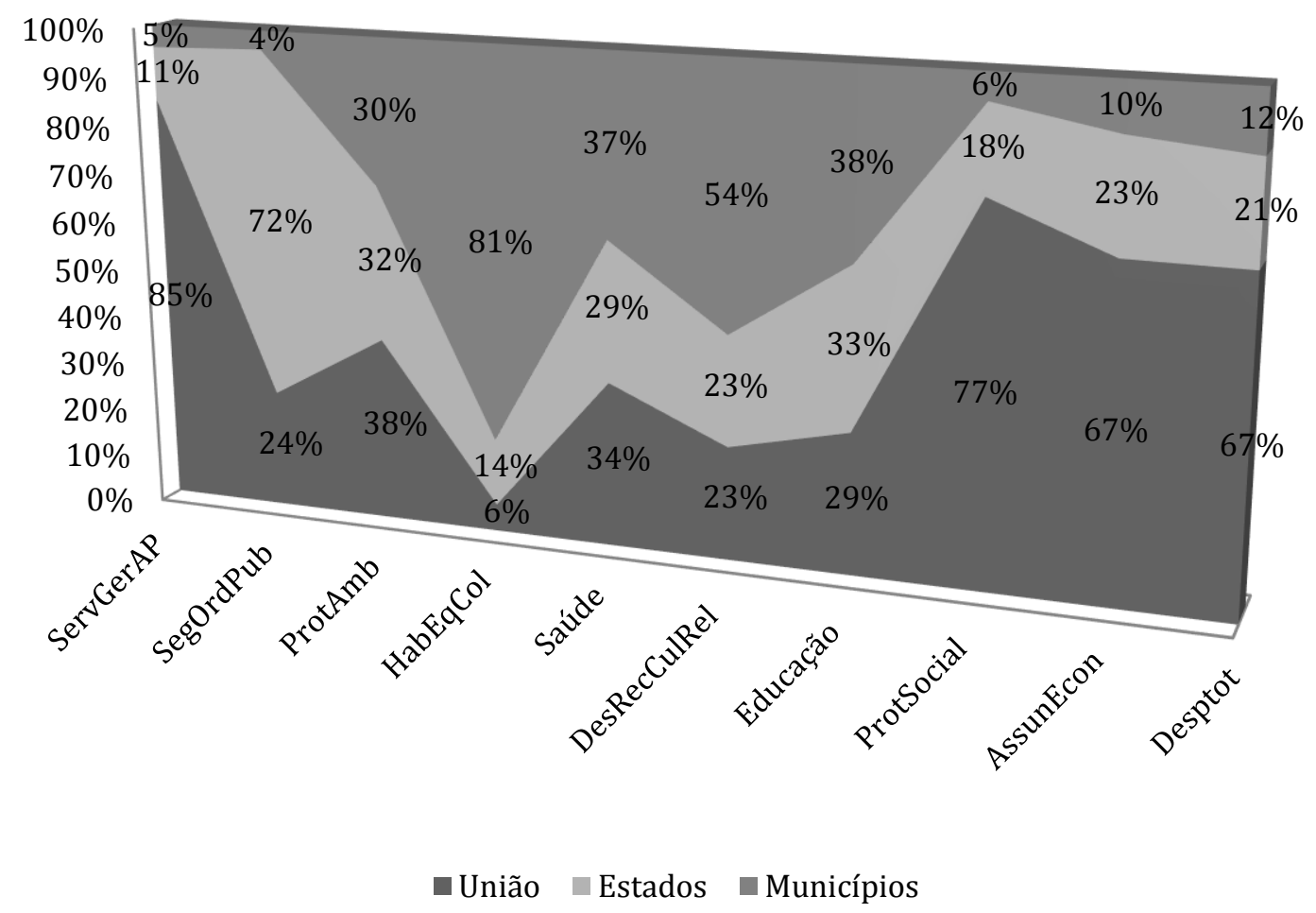

Fonte: Elaborado pelo autor com base no Balanço do Setor Público Nacional do ano de 2016 (BSPN/2016) da Secretaria do Tesouro Nacional.

No Brasil, até as eleições gerais de 1998, existia a limitação ${ }^{19}$ de somente um mandato à frente do poder executivo, com a aprovação da Emenda Constitucional n. ${ }^{\circ}$ 16, de 04 de junho de 1997, a limitação passou a ser de dois mandatos consecutivos. Essa liberdade de buscar a reeleição e ao mesmo tempo a proibição de se candidatar a mais de oito anos de mandato consecutivo, não é um traço da personalidade do político, mas é uma característica transitória imposta por uma norma jurídica e que, segundo a literatura (BESLEY; CASE, 1995, ALT et al., 2011, KLEIN; SAKURAI, 2015, VEIGA; VEIGA, 2016), influencia na política fiscal.

\footnotetext{
${ }^{19}$ Outro ponto muito debatido, e controverso, na economia política é o impacto da limitação de mandatos, sobre a condução da política fiscal nos anos eleitorais. Uma ala argumenta que os incumbentes que buscam a reeleição, irão fazer uso de medidas oportunistas para elevarem as suas chances de se manterem no poder. Nesse sentido, Besley e Case (1995), argumentam que os políticos em primeiro mantado buscam construir uma boa reputação nesse período para ampliar as suas chances de reeleição. Para isso, eles fazem uso de manipulações oportunistas nos níveis de despesas totais e impostos, ou seja, criam um CPO. Besley e Case (2003) e Jonhson e Crain (2004) seguem no mesmo caminho. No entanto, Besley e Case (1995) salientam que quando considerado o período governativo como um todo, os governadores em primeiro mandato não diferem dos demais, ou seja, a diferença fica concentrada no período eleitoral. Por outro lado, pode-se argumentar, como fazem Alt et al. (2011), que os políticos que buscam a reeleição, devem, durante a campanha eleitoral, prestar contas aos cidadãos e defender o seu legado, o que limita o comportamento oportunista por parte dos incumbentes. É preciso salientar que Nogare e Ricciuti (2011) ao analisarem 52 nações, constataram que nem sempre o facto do governante não poder buscar a reeleição acarreta em menor oportunismo.
} 
Nakaguma e Bender (2006) estudaram o impacto da aprovação da Emenda da Reeleição no Brasil sobre a política fiscal e constataram que houve um incremento, após essa alteração na legislação, no nível das despesas com transporte por parte dos governadores de estado, entre 1986 e 2002. Klein e Sakurai (2015) evidenciaram que no Brasil há diferenças na condução da política fiscal entre os governantes locais em primeiro e em segundo mandato, sendo que os de primeiro mandato (passíveis de buscarem a reeleição) apresentam menores níveis de despesa total. Contudo, os resultados de Klein (2010), Lautenschlage (2017) e Lautenschlage (aceito para publicação) não corroboram tal fenômeno. Posto isso, é pertinente controlar para essa limitação e para tal utiliza-se a variável Reeleito $o_{\text {it }}$ que indica se o incumbente está no seu segundo mandato à frente da prefeitura $i$ no ano $t$, e, segundo a legislação, impedido de buscar a reeleição.

O vetor Munic compreende variáveis que controlam para essas características demográficas e socioeconômicas dos municípios barriga-verdes e que podem influenciar o nível das despesas públicas. A variável $l P I B_{\text {it }}$ indica o valor do produto interno bruto (PIB) per capita do município $i$ no ano $t$-1. Utiliza-se o valor do PIB defasado para evitar problemas de endogeneidade. Faz-se uso, também, da variável Crescimento $_{\text {it }}$ a qual indica a variação do PIB entre o ano $t$ e $t-1$ do município $i$. Analfabetos $s_{\mathrm{it}}$, que representa a percentagem de indivíduos com mais de 15 anos de idade que são analfabetos, funciona como uma proxy do inverso do capital humano de determinado município. ${ }^{20}$

Santa Catarina é um grande exportador de commodities, como cereais, entretanto, também possui um parque fabril extenso e que abrange diversas áreas de atuação. A existência de uma Santa Catarina rural e outra urbana torna necessário que se controle para essa característica, uma vez que municípios mais urbanos possuem uma estrutura de despesas públicas diferentes das localidades com grande parcela rural. Para se controlar para essa especificidade, faz-se, uso da variável $U r b a n o_{i t}$, que representa a percentagem da população que reside na área urbana. Por fim, $P E S 65_{\text {it }}$, que é a percentagem de população com 65 anos de idade ou mais, ${ }^{21}$ objetiva controlar para a estrutura etária de cada município. Essa questão etária é ainda mais importante, quando se utiliza a classificação funcional das despesas públicas, dado que, populações mais idosas, possuem demandas por bens e serviços públicos diferentes da dos jovens.

\footnotetext{
${ }^{20}$ Martínez-Bravo (2017) também controlou para o nível de estudo médio da população.

${ }^{21}$ Uma versão inicial do vetor Munic $c_{i, t}^{\prime}$ também incluiu a percentagem de população com menos de 15 anos. No entanto, como o período de amostragem é relativamente curto, existindo pouca variação nessas séries, o que cria colinearidade com os efeitos fixos municipais. O teste Variance Inflation Fators (VIF) sugeriu, segundo os valores recomendados por Greene (2012), que essa variável deveria ser excluída da análise.
} 
Revista Catarinense de Economia - RCE

APEC - Associação dos Pesquisadores em Economia Catarinense

$2^{\circ}$ Semestre de 2017 - www.apec.pro.br/rce

\subsection{Método econométrico}

A base de dados utilizada neste artigo é composta por informações de 292 municípios entre os anos de 2003 e 2014 e os modelos a serem estimados são dinâmicos (Modelo 1), ou seja, a variável dependente desfasada $\left(\mathrm{y}_{\mathrm{i}, \mathrm{t}-\mathrm{j}}\right)$ é utilizada como variável explicativa e, ao fazer isso, segundo Verbeek (2008), pode-se incorrer em problemas relacionados à heteroscedasticidade, autocorrelação e endogeineidade. Os estimadores por efeitos fixos ou por efeitos aleatórios poderiam superar esse problema, contudo, é preciso que o horizonte temporal seja elevado, o que não ocorre com a base de dados utilizada nesse trabalho.

Segundo Roodman (2006), para superar esses problemas Arrelano e Bond (1991) elaboraram um método que, primeiramente, retira as diferenças aos estimadores e, posteriormente, envolve aplicação do Método dos Momentos Generalizados (MMG). O Sistema MMG (SMMG), descrito por Arrelano e Bover (1995) e Blundell e Bond (1998), adiciona um pressuposto adicional ao estimador de Arrelano e Bond (1991), no qual as primeiras diferenças dos instrumentos não são correlacionadas com os efeitos fixos. Ao fazer isso, aumenta-se a eficiência, dada a elevação do número de instrumentos, pois agora há um sistema de duas equações composto pela original e a transformada.

Quando se utilizam instrumentos é preciso assegurar que os mesmos sejam exógenos, ou seja, que não estejam correlacionados com o termo de erro, e, para atingir esse objetivo, utilizase o teste de Hansen, que testa para a sobre-identificação dos instrumentos. Para evitar possíveis problemas de endogeneidade entre as características dos prefeitos e do eleitorado, assumiu-se que os traços dos incumbentes - Esquerda, Feminino e Superior - são pré-determinados, e para evitar o fenômeno da endogeneidade, aplicou-se o $\mathrm{MMG}^{22}$ a essas variáveis após a retirada da primeira diferença, gerando assim um conjunto de instrumentos diferenciados exógenos para a equação em nível do SMMG.

Com a eficiência do estimador assegurada, é preciso garantir a inferência estatística. Para isso, utiliza-se o procedimento proposto por Windmeijer (2005), que corrige os erros padrão gerados pelo método SMMG e permite que se realizem os testes de hipótese. Quando se está a trabalhar com o método sistema MMG, pode-se esperar que haja autocorrelação de primeira ordem, mas não de segunda, e, em relação a isso, utiliza-se o teste de Arellano-Bond para correlação serial de primeira e segunda ordens.

${ }^{22}$ Opção gmmstyle do comando xtabond2 (Roodman, 2006) do software econométrico Stata 13. 


\section{Resultados empíricos}

Nessa seção, que corresponde à parte empírica, são expostos e analisados os resultados obtidos segundo o método SMMG, para o modelo 1 descrito na seção 3. Nas tabelas 2 e 3 estão expostos esses resultados.

\subsection{Eleições e política fiscal}

Nos anos com eleições, segundo Rogoff e Sibert (1988), é esperável que haja uma elevação no nível de despesas totais, entretanto, como sugerem os resultados expostos na Coluna 5 da Tabela 3, nos anos com sufrágios locais, não há alterações nas despesas totais nos municípios catarinenses, indicando assim, a inexistência da ocorrência de oportunismo. Esse resultado está em linha com as conclusões de Lautenschlage (aceito para publicação), também para os municípios de Santa Catarina, mas destoa das evidências de Sakurai e Menezes-Filho (2011) para as localidades brasileiras, e de Nakaguma e Bender (2006) e Lautenschlage (2017) para os governos estaduais do Brasil.

Para testar a hipótese descrita por Rogoff (1990), na qual os incumbentes realizam alterações na composição da despesa antes das eleições, objetivando a reeleição, foram investigadas como as nove funções da despesa são influenciadas pelas eleições e/ou pelos traços pessoais dos prefeitos catarinenses. Nas colunas de 1 a 5 da Tabela 2 e nas colunas 1 a 4 da Tabela 3 são expostos os resultados estimados para as nove funções da despesa segundo a classificação do FMI. Esses resultados sugerem, que a única componente a apresentar elevação no ano eleitoral, face aos demais e tudo o resto estando igual, é a da despesa com habitação e equipamentos coletivos (Coluna 4 da Tabela 2), que, em anos com votações locais, apresenta um incremento médio de 29 reais por habitante. Esse resultado não surpreende, pelo fato de que essa categoria de despesa é a que apresenta maior visibilidade aos cidadãos. Reformas em ruas, praças, etc., são percebidos facilmente pela população. 
Tabela 2 - Ciclos políticos orçamentários - despesas na classificação funcional ( $1^{\mathrm{a}}$ parte)

\begin{tabular}{|c|c|c|c|c|c|}
\hline Variáveis & $\begin{array}{c}(1) \\
\text { ServGerAp }\end{array}$ & $\begin{array}{c}(2) \\
\text { SegOrdPub }\end{array}$ & $\begin{array}{c}(3) \\
\text { ProtAmb }\end{array}$ & $\begin{array}{c}(4) \\
\mathrm{HabEqCol}\end{array}$ & $\begin{array}{c}(5) \\
\text { Saude }\end{array}$ \\
\hline Eleição & $\begin{array}{c}-0.776 * * * \\
(-3.695)\end{array}$ & $\begin{array}{c}-0.0458 * * \\
(-2.403)\end{array}$ & $\begin{array}{c}-0.00253 \\
(-0.292)\end{array}$ & $\begin{array}{c}0.294 * * * \\
(2.995)\end{array}$ & $\begin{array}{c}-0.338 * * \\
(-2.164)\end{array}$ \\
\hline Esquerda & $\begin{array}{c}-0.460 \\
(-0.505)\end{array}$ & $\begin{array}{l}-0.0230 \\
(-0.230)\end{array}$ & $\begin{array}{c}0.0769 * * \\
(2.068)\end{array}$ & $\begin{array}{c}0.136 \\
(0.179)\end{array}$ & $\begin{array}{c}-0.303 \\
(-0.467)\end{array}$ \\
\hline Feminino & $\begin{array}{c}0.781 \\
(1.590)\end{array}$ & $\begin{array}{l}-0.0132 \\
(-0.326)\end{array}$ & $\begin{array}{c}-0.0430 * * \\
(-2.571)\end{array}$ & $\begin{array}{c}0.145 \\
(0.544)\end{array}$ & $\begin{array}{c}1.006 * * \\
(2.157)\end{array}$ \\
\hline Superior & $\begin{array}{c}0.550^{* *} \\
(2.425)\end{array}$ & $\begin{array}{l}0.0133 \\
(0.614)\end{array}$ & $\begin{array}{c}0.00656 \\
(0.429)\end{array}$ & $\begin{array}{c}0.391 * * \\
(2.285)\end{array}$ & $\begin{array}{c}0.537 * * * \\
(2.866)\end{array}$ \\
\hline Reeleito & $\begin{array}{l}-0.236 \\
(-1.481)\end{array}$ & $\begin{array}{c}-0.0448 * * * \\
(-2.835)\end{array}$ & $\begin{array}{c}-0.00255 \\
(-0.229)\end{array}$ & $\begin{array}{l}-0.0379 \\
(-0.343)\end{array}$ & $\begin{array}{l}0.00123 \\
(0.0108)\end{array}$ \\
\hline Pres & $\begin{array}{c}0.252 \\
(0.246)\end{array}$ & $\begin{array}{l}0.0292 \\
(0.241)\end{array}$ & $\begin{array}{l}-0.0439 \\
(-1.110)\end{array}$ & $\begin{array}{c}-0.0408 \\
(-0.0496)\end{array}$ & $\begin{array}{c}-0.188 \\
(-0.260)\end{array}$ \\
\hline Gov & $\begin{array}{c}-0.335 \\
(-1.557)\end{array}$ & $\begin{array}{l}-0.0174 \\
(-1.093)\end{array}$ & $\begin{array}{l}0.0107 \\
(0.968)\end{array}$ & $\begin{array}{c}0.194 \\
(1.554)\end{array}$ & $\begin{array}{c}-0.454 * * * \\
(-2.974)\end{array}$ \\
\hline 1PIB & $\begin{array}{c}6.52 \mathrm{e}-05^{* * * *} \\
(3.339)\end{array}$ & $\begin{array}{c}3.80 \mathrm{e}-06^{* * * *} * \\
(5.209)\end{array}$ & $\begin{array}{c}1.02 \mathrm{e}-06 \\
(1.058)\end{array}$ & $\begin{array}{c}4.39 \mathrm{e}-05^{* * * *} \\
(3.700)\end{array}$ & $\begin{array}{c}\text { 7.35e-05**** } \\
(4.019)\end{array}$ \\
\hline Crescimento & $\begin{array}{c}3.83 \mathrm{e}-05^{* * * *} \\
(3.941)\end{array}$ & $\begin{array}{c}1.41 \mathrm{e}-06 \\
(1.559)\end{array}$ & $\begin{array}{c}1.09 \mathrm{e}-06 \\
(1.051)\end{array}$ & $\begin{array}{c}-3.59 \mathrm{e}-06 \\
(-0.549)\end{array}$ & $\begin{array}{c}3.41 \mathrm{e}-05^{* * * *} \\
(3.766)\end{array}$ \\
\hline PES65 & $\begin{array}{c}35.46 * * * \\
(4.755)\end{array}$ & $\begin{array}{c}-0.965^{* *} \\
(-2.188)\end{array}$ & $\begin{array}{c}0.176 \\
(0.534)\end{array}$ & $\begin{array}{c}8.024 * * \\
(1.975)\end{array}$ & $\begin{array}{c}38.44 * * * \\
(4.732)\end{array}$ \\
\hline Urbano & $\begin{array}{c}-3.662 * * * \\
(-5.199)\end{array}$ & $\begin{array}{c}0.178 * * * \\
(3.859)\end{array}$ & $\begin{array}{c}0.0614 * * \\
(2.512)\end{array}$ & $\begin{array}{c}0.872^{* * *} \\
(2.238)\end{array}$ & $\begin{array}{c}-2.907 * * * \\
(-4.555)\end{array}$ \\
\hline Analfabetos & $\begin{array}{c}16.28 * * * \\
(3.194)\end{array}$ & $\begin{array}{c}-0.768 * * \\
(-2.396)\end{array}$ & $\begin{array}{l}0.0262 \\
(0.151)\end{array}$ & $\begin{array}{c}-3.203 \\
(-1.368)\end{array}$ & $\begin{array}{c}10.51 * * \\
(2.586)\end{array}$ \\
\hline$Y_{t-1}$ & $\begin{array}{c}0.0308 \\
(0.834)\end{array}$ & $\begin{array}{c}0.00756 \\
(1.048)\end{array}$ & $\begin{array}{c}0.535 * * * \\
(4.182)\end{array}$ & $\begin{array}{c}0.183^{* *} \\
(2.124)\end{array}$ & $\begin{array}{c}0.206 \\
(1.553)\end{array}$ \\
\hline Constante & $\begin{array}{c}2.419 * * \\
(2.212)\end{array}$ & $\begin{array}{l}0.110^{*} \\
(1.701)\end{array}$ & $\begin{array}{l}-0.0351 \\
(-0.725)\end{array}$ & $\begin{array}{c}0.117 \\
(0.204)\end{array}$ & $\begin{array}{c}1.204 \\
(1.510)\end{array}$ \\
\hline Observações & 2,484 & 2,412 & 2,282 & 2,480 & 2,459 \\
\hline Municípios & 292 & 292 & 292 & 292 & 292 \\
\hline hansenp & 0.256 & 0.391 & 0.235 & 0.654 & 0.286 \\
\hline $\operatorname{ar} 1 p$ & 0.310 & 0.252 & 0.0101 & 0.167 & 0.267 \\
\hline $\operatorname{ar} 2 p$ & 0.517 & 0.909 & 0.686 & 0.302 & 0.349 \\
\hline
\end{tabular}

Notas: - Estatística t entre parênteses.- Níveis de significância *10\%, ** 5\% e *** 1\%. O Teste de Hansen testa a exogeneidade dos instrumentos, sob a hipótese nula, de que os instrumentos são exógenos, esta estatística do teste segue a distribuição $\chi_{\mathrm{L}-\mathrm{K}}^{2}$, onde L $-\mathrm{K}$ é igual ao número de restrições sobre-identificadas.- Considerou-se que as variáveis $I P I B$, Crescimento, Esquerda, Feminino, Superior, Reeleito, Pres e Gov são pré-determinadas e desta forma foi aplicado GMM às mesmas, sendo que as lags variaram de 1 à 6. - Os defasamento da variável dependente variaram de 2 à 6.- AR1p e AR2p representam os p-valores dos testes para correlação serial de primeira ordem e segunda ordem nos resíduos da primeira diferença, assimptoticamente distribuídos como $\mathrm{N}(0,1)$ sobre a hipótese nula de haver correlação serial. 
Revista Catarinense de Economia - RCE

APEC - Associação dos Pesquisadores em Economia Catarinense

$2^{\circ}$ Semestre de 2017 - www.apec.pro.br/rce

Tabela 3 - Ciclos políticos orçamentários - despesas na classificação funcional (2a parte)

\begin{tabular}{|c|c|c|c|c|c|}
\hline Variáveis & $\begin{array}{c}\text { (1) } \\
\text { DesRecCulRel }\end{array}$ & $\begin{array}{c}\text { (2) } \\
\text { Educação }\end{array}$ & $\begin{array}{c}\text { (3) } \\
\text { ProtSocial }\end{array}$ & $\begin{array}{c}\text { (4) } \\
\text { AssunEcon }\end{array}$ & $\begin{array}{c}\text { (5) } \\
\text { DespTot }\end{array}$ \\
\hline \multirow[t]{2}{*}{ Eleição } & 0.0340 & $-0.362^{3 * *}$ & $-0.0827 * *$ & 0.103 & $-1.213^{*}$ \\
\hline & (1.310) & $(-2.120)$ & $(-2.523)$ & $(0.978)$ & $(-1.780)$ \\
\hline \multirow[t]{2}{*}{ Esquerda } & -0.0722 & 0.404 & -0.0227 & -1.196 & -0.970 \\
\hline & $(-0.794)$ & $(0.537)$ & $(-0.101)$ & $(-1.394)$ & $(-0.293)$ \\
\hline \multirow[t]{2}{*}{ Feminino } & $0.126^{*}$ & $1.667 * * *$ & 0.106 & 0.416 & $4.282 * *$ \\
\hline & $(1.737)$ & $(2.705)$ & $(0.637)$ & $(1.552)$ & $(2.370)$ \\
\hline \multirow[t]{2}{*}{ Superior } & $0.0887 * *$ & $0.433^{*}$ & 0.0442 & 0.366 & $2.817 * * *$ \\
\hline & $(2.374)$ & $(1.861)$ & $(0.785)$ & $(1.571)$ & $(3.026)$ \\
\hline \multirow[t]{2}{*}{ Reeleito } & -0.0186 & -0.222 & -0.0437 & 0.282 & -0.714 \\
\hline & $(-0.603)$ & $(-1.541)$ & $(-1.434)$ & (1.297) & $(-1.070)$ \\
\hline \multirow[t]{2}{*}{ Pres } & 0.0273 & -0.634 & -0.0578 & 0.278 & -1.316 \\
\hline & $(0.269)$ & $(-0.743)$ & $(-0.244)$ & $(0.305)$ & $(-0.331)$ \\
\hline \multirow[t]{2}{*}{ Gov } & -0.0438 & $-0.446^{* *}$ & $-0.142 * *$ & $0.430 * *$ & -0.860 \\
\hline & $(-1.102)$ & $(-2.476)$ & $(-2.501)$ & $(2.286)$ & $(-1.182)$ \\
\hline 1PIB & $\begin{array}{c}1.12 \mathrm{e}-05^{* * * *} \\
(4786)\end{array}$ & $9.66 \mathrm{e}-05^{* * * *}$ & $1.05 \mathrm{e}-05^{*}$ & 4.27e- $05 * * *$ & $0.000387 * * *$ \\
\hline \multirow[t]{2}{*}{ Crescimento } & $3.64 \mathrm{e}-06$ & $4.93 \mathrm{e}-05^{* * *}$ & $4.41 \mathrm{e}-06^{*}$ & $1.68 \mathrm{e}-05$ & $0.000187 * * *$ \\
\hline & $(1.239)$ & (5.657) & $(1.715)$ & $(0.937)$ & $(5.715)$ \\
\hline \multirow[t]{2}{*}{ PES65 } & $5.828 * * *$ & $36.69 * * *$ & $7.102 * * *$ & $32.51 * * *$ & $185.0 * * *$ \\
\hline & $(4.739)$ & $(5.537)$ & $(4.237)$ & $(3.695)$ & $(5.441)$ \\
\hline \multirow[t]{2}{*}{ Urbano } & $-0.368 * * *$ & $-2.813 * * *$ & -0.0586 & $-5.102 * * *$ & $-18.02 * * *$ \\
\hline & $(-4.570)$ & $(-4.551)$ & $(-0.437)$ & $(-5.543)$ & $(-6.150)$ \\
\hline \multirow[t]{2}{*}{ Analfabetos } & $-1.721 * * *$ & $12.65 * * *$ & $2.243^{* *}$ & $6.543^{*}$ & $41.50^{* *}$ \\
\hline & $(-2.960)$ & $(2.918)$ & $(2.233)$ & $(1.847)$ & (2.279) \\
\hline \multirow[t]{2}{*}{$Y_{t-1}$} & $0.192 * * *$ & 0.0965 & $0.351 * *$ & $0.523 * * *$ & 0.109 \\
\hline & $(2.848)$ & $(1.372)$ & $(2.088)$ & $(6.203)$ & $(1.294)$ \\
\hline \multirow[t]{2}{*}{ Constante } & 0.135 & $2.054 * * *$ & -0.0353 & $1.472 * *$ & $10.40 * * *$ \\
\hline & (0.973) & $(2.627)$ & $(-0.164)$ & (2.165) & $(2.929)$ \\
\hline Observações & 2,484 & 2,469 & 2,484 & 2,484 & 2,498 \\
\hline Municípios & 292 & 292 & 292 & 292 & 292 \\
\hline hansenp & 0.432 & 0.221 & 0.654 & 0.843 & 0.167 \\
\hline $\operatorname{ar} 1 \mathrm{p}$ & 0.00158 & 0.296 & 0.220 & 0.000143 & 0.293 \\
\hline $\operatorname{ar} 2 p$ & 0.311 & 0.460 & 0.311 & 0.644 & 0.421 \\
\hline
\end{tabular}

Notas: - Estatística t entre parênteses.- Níveis de significância *10\%, ** 5\% e *** 1\%. O Teste de Hansen testa a exogeneidade dos instrumentos, sob a hipótese nula, de que os instrumentos são exógenos, esta estatística do teste segue a distribuição $\chi_{\mathrm{L}-\mathrm{K}}^{2}$, onde $\mathrm{L}-\mathrm{K}$ é igual ao número de restrições sobre-identificadas.- Considerou-se que as variáveis $l P I B$, Crescimento, Esquerda, Feminino, Superior, Reeleito, Pres e Gov são pré-determinadas e desta forma foi aplicado GMM às mesmas, sendo que as lags variaram de 1 à 6. - Os defasamento da variável dependente variaram de 2 à 6.- AR1p e AR2p representam os p-valores dos testes para correlação serial de primeira ordem e segunda ordem nos resíduos da primeira diferença, assimptoticamente distribuídos como $\mathrm{N}(0,1)$ sobre a hipótese nula de haver correlação serial.

As despesas com segurança e ordem pública, saúde, educação e proteção social, apresentam, por sua vez, reduções no anos com sufrágios municipais. A magnitude dessa redução é de aproximadamente 4,6 reais por habitante com segurança e ordem pública, 33,8 reais por habitante com saúde, 36,2 reais com educação e 8,27 reais por habitante com proteção social. Essas componentes da despesa pública, diferentemente da com habitação e equipamentos coletivos, não é notada pelos cidadãos de maneira direta e clara, dado que, na maioria das vezes, esses dispêndios incorporam remuneração de servidores, os quais não são 
de conhecimento da maioria da população. Por fim, as despesas com proteção ambiental, desportos, recreação, cultura e religião, não apresentam comportamento diferente em anos com eleições municipais, tudo o resto estando igual.

\subsection{Traços dos prefeitos e política fiscal}

No que se refere à influência dos traços dos prefeitos (ideologia de esquerda, gênero, formação superior, impossibilidade de buscar a reeleição, alinhamento político ao presidente da República e alinhamento político ao governador de Santa Catarina) nas despesas públicas dos municípios catarinenses, os resultados estimados indicam que, à exceção do fato de o prefeito municipal ser do mesmo partido do presidente da República, todos os traços têm influência sobre a composição da despesa pública.

Os municípios administrados por prefeitos de partidos de esquerda apresentam em média, quando comparados aos demais e tudo o resto permanecendo igual, maiores níveis médios de despesas com as funções proteção ambiental (+7,7 reais por habitante). Kneebone e Mckenzie (2001), evidenciaram um aumento no desvio das despesas sociais nos municípios administrados por partidos de esquerda, nas províncias canadenses, fenômeno esse que não ocorre nos municípios do estado de Santa Catarina, dado que, como demonstram as Tabelas 2 e 3, essas despesas (saúde, educação e proteção social) não são influenciadas pelo fato de o prefeito ser de uma agremiação política de esquerda, tudo o resto estando igual.

O fato da localidade ser governada por uma mulher, acarreta, em média e tudo o resto permanecendo igual, um incremento de 100 reais por habitante com despesas de saúde, 166 reais por habitante com educação e 428 reais por habitante com despesas totais. Por outro lado, as despesas com proteção ambiental apresentam redução de, em média, 4,3 reais por habitante em municípios administrados por prefeitas. Besley e Case (2003), Jacobsen (2006), ClotsFigueras (2012) e Park (2014) constataram que o fato do governo ser encabeçado por mulheres, impacta numa alteração da composição da despesa com primazia pelos gastos voltados às áreas sociais, o que, segundo indicam os resultados das Tabelas 2 e 3, também ocorre no caso catarinense.

Chattopadhyay e Duflo (2004), por sua vez, constataram que mulheres à frente dos governos regionais na Índia apresentavam maiores níveis de despesas com a construção de estradas e com provisão de água. No caso dos municípios brasileiros, as prefeitas despendem, tudo o resto estando igual, menos que os homens com a função habitação e equipamentos coletivos (coluna 4 da Tabela 2), que engloba justamente as despesas com fornecimento de 
água, tratamento de esgotos e gastos com estradas e ruas. De forma geral, os resultados estimados sugerem que o fato de eleger uma mulher para a chefia do poder executivo local, não representará, no caso catarinense, uma elevação nas despesas por habitante com despesas com habitação e equipamentos coletivos.

Os prefeitos com, no mínimo, o ensino superior completo, apresentam, quando comparados aos demais e tudo o resto estando igual, maiores níveis de despesas com serviços gerais da administração pública (55 reais por habitante), com habitação e equipamentos coletivos $(39,1$ reais por habitante), com saúde (53,7 reais por habitante), com desporto, recreação, cultura e religião (8,87 reais por habitante) e com despesas totais (281,7 reais por habitante). Jacobsen (2006) analisou o impacto dos anos de estudo do incumbente na composição das despesas nos municípios noruegueses e constatou um comportamento divergente do exposto na Tabela 3 para o caso de Santa Catarina, dado que evidenciou uma relação causal entre os anos de estudo do político local norueguês e as despesas com gastos sociais, o que não é observado nos municípios brasileiros, uma vez que não há alteração nessas despesas.

O impedimento legal de concorrer à reeleição foi debatido nos anos de 2015 e 2016, mas acabou por não ser aprovada a limitação de um mandato aos chefes do poder executivo das três esferas de governo. Posto isso, permanece a possibilidade do incumbente buscar um segundo mandato consecutivo. Ao se analisar como os prefeitos catarinenses reeleitos, ou seja, em segundo mandato consecutivo, agem perante os níveis e composição da despesa pública, os resultados indicam (coluna 2 da Tabela 2) que somente as despesas com segurança e ordem pública são influenciadas por essa característica. Os mandatários locais impedidos de buscar mais um mandato consecutivo despendem, em média, e quando comparados aos demais e tudo o resto permanecendo igual, menos 4,4 reais por habitante com essa rubrica.

Os resultados estimados e expostos nas Tabelas 2 e 3 sugerem que os prefeitos do mesmo partido do presidente da República não agem diferentemente dos demais, tudo o resto ficando igual. Por sua vez, o alinhamento político entre o prefeito e o governador catarinense parece apresentar influência sobre a composição da despesa.

Municípios administrados por prefeitos do mesmo partido do governador de Santa Catarina despendem, em média, mais 43 reais por habitante com assuntos econômicos, menos 45,4 reais por habitante com saúde, menos 44,6 reais por habitante com educação e menos 14,2 reais por habitante com proteção social. Esses resultados sugerem que esses prefeitos estão inclinados a despender com assuntos econômicos em detrimento das despesas com a área social, como saúde, educação e proteção social. Sakurai (2009), diferentemente deste trabalho, obteve resultados opostos no que concerne aos gastos com habitação, uma vez que ele concluiu que prefeitos da 
mesma agremiação partidária do governador de estado apresentam menores níveis de despesas com urbanismo, o que, segundo a classificação utilizada neste trabalho, está inserido na função habitação.

\subsection{Traços dos municípios e política fiscal}

O estado de Santa Catarina, assim como o Brasil, possui diferenças socioeconômicas e demográficas significativas. Há municípios mais desenvolvidos e outros menos, alguns com elevada população jovem, outros com maior parcela de idosos, assim como certas localidades são majoritariamente rurais e outras são urbanas.

No estudo de como o nível do produto interno bruto do município e a taxa de variação do mesmo influencia as despesas públicas e sua composição, os resultados estimados e expostos nas Tabelas 2 e 3 sugerem que à exceção das despesas com proteção ambiental e com proteção social, todas as componentes da despesa pública, inclusive a despesa total, são influenciadas positivamente pelo nível defasado do PIB do município. Já a variação no produto de um ano para o outro, conforme sugerem os resultados expostos nas Tabelas 2 e 3, apresenta relação causal positiva com os níveis de despesas totais, com serviços gerais da administração pública, com saúde e com educação.

Ao se migrar para as características demográficas, os resultados sugerem que os municípios com maior parcela da população com mais de 65 anos, apresenta, ceteris paribus, maiores níveis de despesa total, assim como maiores níveis de dispêndios com serviços da administração pública, com habitação e equipamentos coletivos, saúde, desportos, recreação, cultura e religião, educação, proteção social e assuntos econômicos, e menos com segurança e ordem pública.

Já os municípios com maior porcentagem da população a residir em zonas urbanas, apresentam, ceteris paribus, menores níveis de despesas totais e de despesas com serviços gerais da administração pública, saúde, desportos, recreação, cultura e religião, educação e assuntos econômicos, mas apresentam maiores gastos com segurança e ordem pública, proteção ambiental e habitação e equipamentos coletivos. Todas essas componentes da despesa que apresentam relação direta com a porcentagem de população a residir em zonas urbanas, são dispêndios intimamente relacionados com a zona urbana, ou seja, era esperado que reagissem dessa maneira.

Por fim, a parcela da população analfabeta, segundo os resultados expostos nas Tabelas 2 e 3, apresenta relação causal com a despesa total, despesas com serviços gerais da administração 
pública, gastos com segurança e ordem pública, saúde, desportos, recreação, cultura e religião, educação e proteção social.

\section{Conclusões}

Este trabalho tinha como objetivo analisar como as eleições e determinados traços dos prefeitos e influenciam na condução da política fiscal dos municípios catarinenses. Para atingilo, foram realizadas algumas regressões para testar se existe, ou não, esse efeito causal. Os resultados obtidos não sustentam a hipótese de incremento nas despesas totais dos municípios catarinenses nos anos com sufrágios locais, como descrito por Rogoff e Sibert (1988). Os resultados indicam, por outro lado, que os prefeitos catarinenses elevam as despesas com habitação e equipamentos coletivos. Esse resultado confirma a ideia de Rogoff (1990), na qual os políticos manipulam a composição das despesas para sinalizar maior competência aos cidadãos e, assim, conseguirem a reeleição, sendo essa componente da despesa uma das mais bem recebidas e percebidas pela população.

Uma das inovações deste trabalho é estudar como os traços dos prefeitos influenciam na condução da política fiscal, com especial interesse pela composição da despesa pública dos municípios catarinenses. Os resultados estimados sugerem que a ideologia, o gênero, a formação superior, a impossibilidade de reeleição e o alinhamento político ao governador do estado de Santa Catarina, influenciam nos níveis das despesas. Já o alinhamento ao presidente da República, não apresentou impacto. Esses resultados são importantes, pois, consoante cada traço pessoal, há a possibilidade de haver alterações na composição da despesa, permitindo, no limite, que os eleitores escolham o seu candidato à chefia do poder executivo local com base nas suas características pessoais.

Encontraram-se evidências, também, de que o nível do produto passado e a sua variação influenciam grande parte das funções da despesa, assim como a despesa total. O mesmo ocorre com a parcela da população idosa, que reside nas zonas urbanas e é analfabeta.

Para trabalhos futuros seria importante estudar se o oportunismo compensa, tanto em Santa Catarina como no Brasil.

\section{Referências}

AIDT, T.S.; VEIGA, F. J.; VEIGA. L. G. Election results and opportunistic policies: a new test of the rational political business cycle model. Public Choice, n. 148, p. 21-44, 2011.

ALBOUY, D. Partisan representation in Congress and the geographic distribution of federal funds.

The Review of Economics and Statistics, v.95, n. 1, p. 127-141, 2013.

ALESINA, A. Macroeconomic policy in a two-party system as a repeated game. Quarterly Journal 
Revista Catarinense de Economia - RCE

APEC - Associação dos Pesquisadores em Economia Catarinense

$2^{\circ}$ Semestre de 2017 - www.apec.pro.br/rce

of Economics, n. 2, p. 651-78, 1987.

ALESINA, A.; GIULIANO, P. Preferences for redistribution, NBER Working Paper, n. 14825, 2009, p. 1-38.

ALESINA, A.; LA FERRARA, E. Ethnic diversity and economic performance. Journal of Economic Literature, v.43, n. 3, p. 762- 800, 2005.

ALESINA, A.; TABELLINI, G. A positive theory of fiscal deficits and government debt. The Review of Economic Studies, v. 57, n.3, p. 403-414, 1990.

Alesina, A.; ROSEnThal, H. Partisan Politics, Divided Government, and the Economy. Cambridge, UK: Cambridge University Press, 1995.

ALESINA, A.; SACHS, J. Political parties and the business cycle in the United States, 1948-1984. Journal of Money, Credit and Banking, v. 20, n. 1, p. 63-82, 1988.

ALESINA, A.; TROIANO, U.; CASSIDY, T. Old and young politicians. NBER Working Paper, 20977, 2015.

ARELLANO, M.; BOND, S. Some tests of specification for panel data: Monte Carlo evidence and an application to employment equations. The Review of Economic Studies, v. 58, p. 277-297, 1991.]

ARELLANO, M.; BOYER, O. Another look at the instrumental variable estimation of errorcomponent models. Journal of Econometrics, v. 68, p. 29-51, 1995.

BECKER, G. Public policies, pressure groups and deadweight costs. Journal of Public Economics, n. 28, p. 329-347, 1985.

BESLEY, T; CASE, A. Does electoral accountability affect economic policy choices? Evidence from gubernatorial term limits. The Quarterly Journal of Economics, v. 110, n. 3, p. 769-798, 1995.

BESLEY, T; CASE, A. Political institutions and policy choices: evidence from the United States. Journal of Economic Literatura, n.41, p. 7-73, 2003.

BESLEY, T.; MONTALVO, J.G; REYNAL-QUEROL, M. Do educated leaders matter? The Economic Journal, v.121, n.554, p. 205-227, 2011.

BHALOTRA, S.; CLOTS-FIGUERAS, I. Health and the political agency of women. American Economic Journal: Economic Policy, v. 6, n. 2, p. 164-197, 2014.

BLUNDELL, R.; BOND, S. Initial conditions and moment restrictions in dynamic panel data models. Journal of Econometrics, v. 87, p. 115-143, 1998.

BRASIL. Constituição da República Federativa do Brasil. Brasília, 1988.

BRASIL. Lei Complementar $\mathbf{n}^{\mathbf{0}}$ 101, de 04 de maio de 2000.

BROLLO, F.; NANNICINI, T. Tying your enemy's hands in close races: the politics of federal transfers in Brazil. American Political Science Review, v. 106, p. 742-761, 2012.

CARNES, N.; LUPU, N. Rethinking the comparative perspective on class and representation: Evidence from Latin America. American Journal of Political Science, v. 59, n.1, p. 1-18, 2015.

CHATTOPADHYAY, R.; DUFLO, E. Women as policy makers: evidence from a randomized policy experiment in India, Econometrica, v. 72, n. 5, p. 1409-1443, 2004.

CHORTAREAS, G.; LOGOTHETIS, V.; PAPANDREOU, A. A. Political budget cycles and reelection prospects in Greece's municipalities. European Journal of Political Economy, v. 43, p. $1-13,2016$.

CLOTS-FIGUERAS, I. Are Female Leaders Good for Education? Evidence from India. American Economic Journal: Applied Economics, v. 4, n. 1, 212-44, 2012.

CORNEO, G.; GRUNER, H. P. Individual preferences for political redistribution. Journal of Public Economics, v. 83, p. 83-107, 2002.

COX, G.W.; MCCUBBINS, M. Electoral politics as a redistributive game. Journal of Politics, v. 48, n.2, p. 370-389, 1986.

DRAZEN, A.; ESLAVA, M. Electoral manipulation via voter-friendly spending: theory and evidence. Jornal of development economics, v. 92, p. 39-52, 2010.

DREHER, A., LAMLA, M. J., RUPPRECHT, S. M., SOMOGYI, F. The impact of political leaders' profession and education on reforms. Journal of Comparative Economics, n. 37, p. 169-193, 2009.

FERREIRA, F.; GYOURKO, J. Does gender matter for political leadership? The case of U.S. mayors. Journal of Public Economics, v. 112, p. 24-39, 2014.

FERREIRA, I. F. S.; BUGARIN, M. S. Transferências voluntárias e ciclo político-orçamentário no federalismo fiscal brasileiro. Revista Brasileira de Economia, v. 61, n. 3, p. 271-300, 2007. 
FREY, B. S.; SCHNEIDER, F. An empirical study of politico-economic interaction in the United States. Rev. Econ. Stat. n. 60, p. 1974-2183, 1978a.

FREY, B. S.; SCHNEIDER, F. A politic-economic model of the United Kingdom. Econ. J. n. 88, p. 243-253, 1978b.

GREENE, W. Econometric analysis. 7th ed. London: Pearson, 2012.

GROSSMAN, G.M.; HELPMAN, E. Electoral competition and special interest politics. The Review of Economic Studies, v.63, n.2, p. 265-86, 1996.

GUILLAMÓN, M. D.; BASTIDA, F.; BENITO, B. The electoral budget cycle on municipal police expenditures. European Journal of Law Economics, n.36, p. 447-469, 2013.

HANSEN, L. P. Large sample properties of generalized method of moment's estimator. Econometrica, v. 50, n. 4, p. 1029-1054, 1982.

HAYO, B.; NEUMEIER, F. Leaders' impact on public spending priorities: the case of the German Laender. Kyklos, v. 65, n. 4, p. 480-511, 2012.

HAYO, B.; NEUMEIER, F. Political leaders' background and fiscal performance in Germany.

European Journal of Political Economy, v. 34, p. 184-205, 2014.

HERWARTZ, H.; THEILEN, B. Partisan influence on social spending under market integration, fiscal pressure and institutional change. European Journal of Political Economy, n.34, p. 409-424, 2014.

HIBBS, D. PolItical parties and macroeconomic policy. The American Political Science Review, v. 7, p. 1467-148, 1977

JACOBSEN, D. I. Public sector growth: comparing politicians' and administrators' spending preferences. Public Administration, v. 84, n. 1, p. 185-204, 2006.

JONES, B.; OLKEN, B. Do leaders matter? National leadership and growth since World War II. Quarterly Journal of Economics, v. 120, n. 3, p. 835-64, 2005.

JOHNSON, J. M.; CRAIN, W. M. Effects of Term Limits on Fiscal Performance: Evidence from Democratic Nations. Public Choice, v. 119, n.1-2, p. 73-90, 2004.

KALSETH, J.; RATTSO, J. Political control of administrative spending: the case of local governments in Norway. Economics and Politics, v. 1, n.10, p. 63-83, 1998.

KLEIN, F. A. Reelection incentives and political budget cycle: evidence from Brazil. Revista de Administração Pública, v. 44, n. 2, p. 283-337, 2010.

KLEIN, F. A.; SAKURAI, S. N. Term limits and political budget cycles at the local level: evidence from a young democracy. European Journal of Political Economy, v. 37, p. 21-36, 2015.

KNEEBONE, R. D.; McKENZIE, K. J. Electoral and partisan cycles in fiscal policy: an examination of Canadian provinces, Internation Tax and Public Finance, v. 8, p. 753-774, 2001.

LAUTENSCHLAGE, J. Políticos, eleições e receitas públicas. Textos de economia, v. 19, n. 1, p. 2447, 2016.

LAUTENSCHLAGE, J. Impacto da Lei de Responsabilidade Fiscal sobre os ciclos políticoorçamentários e os níveis de despesas e receitas nos estados brasileiros. Economic Analysis of Law Review, v.8, n.2, p. 317-350, 2017.

LAUTENSCHLAGE, J. Ciclo político-econômicos nos municípios de Santa Catarina. Textos de economia. (aceito para publicação).

LINDBECK, A.; WEIBULL, J. Balanced-budget redistribution as the outcome of political competition. Public Choice, n. 52, p. 273-97, 1987.

LINDBECK, A.; WEIBULL, J. A model of political equilibrium in a representative democracy. Journal of Public Economics, n. 51, p. 195-209, 1993.

MAINWARING, S. P. Rethinking party systems in the third wave of democratization: the case of Brazil. Palo Alto: Stanford University Press, 1999.

MARTÍNEZ-BRAVO, M. The local political economy effects of school construction in Indonesia. American Economic Journal, v. 9, n. 2, p. 256-289, 2017.

MOESSINGER, M. D. Do the personal characteristics of finance ministers affect changes in public debt? Public Choice, v. 161, n. 1-2, p. 183-207, 2014.

NAKAGUMA, M. Y.; BENDER, S. A Emenda da Reeleição e a Lei de Responsabilidade Fiscal: impactos sobre ciclos políticos e performance fiscal dos estados (1986-2002). Economia Aplicada, v. 10, n. 3, p. 377-397, 2006. 
NOGARE, C. D.; RICCIUTI, R. Do term limits affect fiscal policy choices? European Journal of Political Economy, v. 27, n. 11, p. 681-692, 2011.

NORDHAUS, W. The political business cycle. Review of Economic Studies, v. 42, p. 169-190, 1975.

OLSON, M. The logic of collective action. Cambridge, MA: Harvard University Press, 1965.

PANDE, R. Can mandated political representation increase policy influence for disadvantaged minorities? Theory and evidence from India. The American Economic Review v. 93, n. 4, p. 1132-1151, 2003.

PARK, S. The politics of redistribution in local governments: the effect of gender representation on welfare spending im California counties. Journal of Public Policy, v. 34, n. 2, p. 269-301, 2014.

PERSSON, T.; TABELLINI; G. The economic effect of constitutions: what do the data say. Cambridge: MIT Press, 2003.

PETTERSSON-LIDBOM, P. Do parties matter for economic outcomes? A Regression Discontinuity approach. Journal of the European Economic Association n.6, p. 1037-1056, 2008.

POTRAFKE, N. Political cycles and economic performance in OCDE countries: empirical evidence from 1951-2006. Public Choice, n. 150, p. 155-179, 2012.

REHAVI, M. M. Sex and politics: do female legislators affect state spending? Mimeo, University of California Berkeley, 2007.

ROODMAN, D. How to do xtabond2: An introduction to difference and system GMM in Stata. Stata Journal, v.9, n.1, p. 86-136, 2009.

ROGOFF, K. Equilibrium polítical budget cycles. American Economic Review, v. 80, p. 21-36, 1990.

ROGOFF, K.; SIBERT, A. Elections and macroeconomic policy cycles. Review of Economics Studies, v. 55, p. 1-16, 1988.

SAKURAI, S. N. Ciclos políticos nas funções orçamentárias dos municípios brasileiros: uma análise para o período 1990 - 2005 via dados em painel. Estudos Econômicos, v. 39, n. 1, p. 39-58, 2009.

SAKURAI, S. N.; MENEZES FILHO, N. Opportunistic and partisan election cycles in Brazil: new evidence at the municipal level. Public Choice, n. 148, p. 233-247, 2011.

SVALERYD, H. Women's representation and public spending. European Journal of Political Economy, v.25, n. 2, p. 186-198, 2009.

VEIGA, L. G.; PINHO, M. M. The political economy of intergovernamental grants: Evidence from a maturing democracy. Public Choice, n. 133, p 457-477, 2007.

VEIGA, L. G.; VEIGA, F. J. Political business cycles at the municipal level. Public Choice, n. 131, p. 45-64, 2007.

VEIGA, L. G.; VEIGA, F. J. Term limits at the local government level: evidence from a natural experiment. NIPE - WP, n. 07/2016, 2016.

WINDMEIJER, F. (2005). A finite sample correction for the variance of linear two-step GMM estimators. Institute of Fiscal Studies Working Paper Series No W00/19.

ZUCCO, C. Esquerda, direita e governo: a ideologia dos partidos políticos brasileiros. In: POWER, T.; ZUCCO, C. (Orgs.). O Congresso por ele mesmo: autopercepções da classe política brasileira. Belo Horizonte: Ed. UFMG, 2011. 